Ali Hasanpour Dehkordi', Shakiba Gholamzad ${ }^{2}$, Sam Myrfendereski, Ayda Hasanpour Dehkordi ${ }^{4}$, Hourivash Ghaderi ${ }^{5}$

\title{
INVESTIGATING THE EFFECT OF QUARANTINE CAUSED BY COVID-19 ON MENTAL HEALTH AND SOCIAL TRUST
}

\author{
${ }^{1}$ Social Determinants of Health Research Center, School of Allied Medical Sciences, \\ Shahrekord University of Medical Sciences, Shahrekord, Iran \\ ${ }^{2}$ Student Research Committee, Iran University Of Medical Sciences, Tehran ,Iran \\ ${ }^{3}$ Department of Radiology, Isfahan University of Medical Sciences, Isfahan, Iran \\ ${ }^{4}$ Department of Psychology, Shahrekord Azad University, Shahrekord, Iran \\ ${ }^{5}$ Department of Psychiatry, Shahrekord University of Medical Sciences, Shahrekord, Iran
}

\section{ABSTRACT}

PURPOSE. This study was conducted to examine the effect of quarantine caused by COVID-19 on people's mental health and social trust.

METHOD. In this study, the sample size covers 2919 people in the southwest of Iran that was selected cluster sample method and was evaluated online using tools of social trust and a checklist of mental disorder syndrome. RESULTS. Due to the results, COVID-19 affected all people's mental health negatively, but there was a significant difference between the rates of COVID-19 caused anxiety and the dimensions of the psychological problems and social trust different between men and women and married and single people, and also the education level. There was no significant relationship between any of the demographic variables and social trust variables, corona anxiety, and dimensions of psychological problems. And there was a negative and significant relationship between the dimensions of social trust and the dimensions of psychological problems. Moreover, the social trust rate in the subjects was desirable. Based on the results and the cutoff point of 2.5 as a border of healthy and unhealthy psychological dimensions, $4.5 \%$ had pathological anxiety, $7.3 \%$ had pathological depression, $5 \%$ had aggression, and $5.9 \%$ had pathological obsessive-compulsive disorder. Depression had the highest scores, and aggression had the lowest scores.

CONCLUSION. Due to this study's results, policymakers should consider measures that should be taken in crisis to support all people, especially vulnerable people in psychological, economic, social, spiritual, and psychological fields. On the other hand, the government must train the public through the mass media to cope with COVID-19

Keywords: COVID-19 (Corona), quarantine, mental health, social trust

\section{INTRODUCTION}

After increasing the incidence and spread of the coronavirus universally, the WHO announced the new coronavirus outbreak is the sixth leading reason for public health emergency in the world and is considered a threat to all countries (1). According to the reports published by WHO, the coronavirus is a global crisis that has not endangered public health (2). The virus is transmitted through person-to-person contact and is extremely contagious. Consequently, restricting people's contact, social distancing, and quarantine is one of the first preventive measures to break the chain of transmission (3). Recognizing the importance of coronary disease caused that people in some countries to be quarantined or have extensively restricted their commuting. So that people have to stay at home and do not leave the house for many days (4). Hence, some countries had to declare full quarantine (such as China and Italy) or implement preventive care (social distancing) at the macro and national levels (such as Iran, USA, UK, Germany) regionally or generally (5).

Quarantine provides economic, social, and performance limitations. Research explains that quarantine and observing social distancing at the time of the prevalence of epidemic diseases increase 
the possibility of developing into mental illnesses (6). Following these conditions, some factors such as fear of disease, fear of death, broadcasting false news and rumors, interference in daily activities, regulations prohibiting or restricting travel and commuting, reducing social spirits, the occurrence of job and financial problems, and dozens of factors related to these conditions have put at risk the people's mental health in the community (2).

Quarantined people are predisposed to depression, anxiety, sleep disorders, stigmatization, avoidance behaviors, and Post-traumatic stress disorder (PTSD). Some factors also increase the possibility of psychological damages during the quarantine, such as fear of developing into the disease, feelings of inability, boredom, the concern of economic consequences, disease outbreaks, and concern of famine $(1,2)$. The results obtained by a study that examined people's immediate psychological responses to COVID-19 on 1,210 people in 194 centers in China showed a mean prevalence of depression symptoms of $16.5 \%$ and severe $28.8 \%$. Symptoms of moderate to severe anxiety and stress have also been reported. Most respondents spent 20 to 24 hours a day at home (84.7\%) and were worried about their family members (7). Corona can create disappointment, fear, anxiety, and stigma, isolation, depression, irritability, violence, and family problems in people (8).

Social trust can be influenced during quarantine and communication constraints. Furthermore, these conditions and spreading false news and rumors, intervention in daily activities, regulations to prohibit or restrict travel and commuting, reducing social relations with colleagues, friends and even family, job and financial problems and factors related to these conditions (9) may decrease social trust in people in the community (10). The COVID-19 epidemic crisis changes dramatically all aspects of human interactions, such as social trust. There are many socio-economic consequences of the coronavirus epidemic (11). The results of a study conducted by Ki and Huang showed that the trust in society, the people, and the government had been improved because of the Corona, while trust in the religious press and organizations has been reduced (12). The relationship between social and political trust on the one hand and the responses of the government and citizens to the epidemic on the other hand and also trust between the people and the government can be regarded as essential to manage the epidemic (11). Higher social trust results in higher agreement with health policies - such as measures related to quarantine, testing, and restrictions on large groups. In reality, this perspective is consistent with the experience of past epidemics, such as the Ebola outbreak in West Africa in 2014-2016 (13, 14) or the Acute Respiratory Syndrome (SARS) (15).
Considering the importance of individuals' social trust, cooperation, and association in the epidemic conditions, this study was conducted to investigate the effect of quarantine caused by COVID-19 on people's mental health and social trust in southwestern Iran.

\section{METHOD}

This study was descriptive-analytical research that was accepted at Shahrekord University of Medical Sciences after receiving the necessary licenses and with the ethical code of IR.SKUMS.REC.1399.016. The study population covered 2919 people in southwestern Iran. In this study, sampling was performed in the cluster method, and SCL 90 standard scale and social trust scale were used to collect the information. After designing the Android system questionnaire and uploading it in this system, it was sent to the people by message, and the people completed the questionnaire online. SPSS 23 software using descriptive and inferential statistical methods, including t-test, correlation, and regression were applied to analyze data. Symptom checklist -90 - revised, the R-90-SCL questionnaire is used to diagnose psychiatric problems. This questionnaire includes 90 questions to evaluate psychological symptoms and is reported by the respondent. This questionnaire also can diagnose healthy people from patients. Dragotis et al. introduced this questionnaire in 1973. Each question in the questionnaire includes a 5-point range of distress ranging from a score of zero "none" to four "seriously". The questionnaire has made of 9 different dimensions, including physical complaints, obsessive-compulsive disorder, sensitivity in interactions and relationships, depression, anxiety, aggression, the fear of illness, paranoid, and psychosis thoughts. The short form with 48 questions has been used in this study. That measures obsessive-compulsive disorder, sensitivity in relationships, depression, anxiety, and aggression. It was used to determine the prevalence of psychiatric symptoms in each symptom after the cutoff point of 2.5, and the mean score after the cut-off point of 2.5 in each dimension is considered as the disease state. The checklist's validity was achieved at 0.98 and 0.82 , respectively, using internal consistency and retest coefficients by Cronbach's alpha and Pearson correlation (16).

Social Trust Scale: Saffari Nia and Sharif provided this scale, and this scale includes 95 items and 5 dimensions, that 5 questions have been considered for each dimension. Trust-based behavior, collaborative tendencies, explicitness, honesty, and trust form five dimensions of this questionnaire. The subjects responded to the questions based on the 5-point Likert scale (1 completely disagree to 5 completely agree). Cronbach's alpha coefficient related to the social trust scale was achieved equal to 0.954 and Cronbach's alpha 
coefficient related to all 5 dimensions was achieved $0.971,0.971,0.961,0.969$ and 0.967) (17).

\section{RESULTS}

The research results showed that $35.67 \%$ of the studied subjects are male ad 64.33 are female $.45 .71 \%$ are single, and $54.29 \%$ are married (Table I).

Considering the total scores of social trusts, the results indicate that $15 \%$ of the subjects have moderate social trust, and $85 \%$ are very good in terms of social trust. Furthermore, according to the results, $1 \%$ are in the weak level, $26.1 \%$ in the moderate level, and $72.9 \%$ in the very good level in terms of the trust-based behavior. $3 \%$ are at a weak level, $27.1 \%$ are at a moderate level, and $72.6 \%$ are at a very good level considering the component of cooperative tendencies. $0.8 \%$ are at the weak level, $10.7 \%$ at a moderate level, and $88.5 \%$ at the very good level considering the explicitness component. $1.2 \%$ are at the weak level, $49.2 \%$ at the moderate level, and $55.9 \%$ at the very good level in terms of the honesty component. $13.1 \%$ are at the weak level, $47.8 \%$ at the moderate level, and $39.1 \%$ at the very good level in terms of the confidence component. As the obtained scores show, the highest level of social trust obtained belongs to the explicitness component with $88 \%$ at a very good level. The lowest level of social trust belongs to the confidence component, with 39\% (Table II).

Based on cut-off point of 2.5 as the healthy and unhealthy border of psychological dimensions, $95.5 \%$ of the healthy sample and $4.5 \%$ of higher than the set cut-off point have pathological anxiety and $92.7 \%$ of the healthy sample and 7-3\% higher than the set cut-off point have pathological depression, $95 \%$ of the healthy sample and 5\% higher than the set cut-off point have aggression, $92 \%$ of the healthy sample and $7.3 \%$ higher than the set cut-off point have pathological depression and $94.1 \%$ of the healthy sample and $5.9 \%$ higher than the set cut-off point have pathological obsessivecompulsive disorder (Table III).

Considering the dimensions of psychological problems, the results indicated that depression has the

Table I .The results related to the demographic distribution related to the research subjects

\begin{tabular}{|c|c|c|c|}
\hline & & Frequency & Percent \\
\hline \multirow{3}{*}{ Gender } & male & 1004 & 35.7 \\
\hline & female & 1811 & 64.3 \\
\hline & total & 2815 & 100 \\
\hline \multirow{6}{*}{ Education } & High school & 262 & 9.0 \\
\hline & Diploma & 857 & 29.5 \\
\hline & Bachelor & 1317 & 45.3 \\
\hline & Masters & 294 & 10.1 \\
\hline & Phd & 85 & 3.1 \\
\hline & Total & 2815 & 100 \\
\hline \multirow{3}{*}{ Marital status } & single & 1287 & 45.7 \\
\hline & married & 1528 & 54.3 \\
\hline & total & 2815 & 100 \\
\hline \multirow{3}{*}{ Accommodation } & private house & 2151 & 77.3 \\
\hline & rented house & 631 & 22.7 \\
\hline & Total & 2782 & 100.0 \\
\hline \multirow{5}{*}{ Numberroom } & 1 & 351 & 12.5 \\
\hline & 2 & 1483 & 52.6 \\
\hline & 3 & 813 & 28.9 \\
\hline & more than 3 & 171 & 6.1 \\
\hline & Total & 2818 & 100.0 \\
\hline \multirow{6}{*}{$\begin{array}{l}\text { Number } \\
\text { Of family }\end{array}$} & 1 & 100 & 3.5 \\
\hline & 2 & 335 & 11.9 \\
\hline & 3 & 619 & 22.0 \\
\hline & 4 & 1088 & 38.6 \\
\hline & more than 4 & 675 & 24.0 \\
\hline & Total & 2817 & 100.0 \\
\hline
\end{tabular}


Ali Hasanpour Dehkordi, Shakiba Gholamzad, Sam Myrfendereski et al.

Table II: The results related to the components of social trust variable

\begin{tabular}{|c|c|c|c|}
\hline Social trust component & Range & Frequency & Percent \\
\hline \multirow{3}{*}{ Trust-based behavior } & $(5-10)$ weak & 29 & 1.0 \\
\cline { 2 - 4 } & $(10-15)$ average & 753 & 26.1 \\
\cline { 2 - 4 } & $(15-25)$ good & 2106 & 72.9 \\
\hline \multirow{3}{*}{ Collaborative tendencies } & $(5-10)$ weak & 9 & .3 \\
\cline { 2 - 4 } & $(10-15)$ average & 784 & 72.1 \\
\cline { 2 - 4 } & $(15-25)$ good & 2103 & .8 \\
\hline \multirow{3}{*}{ Explicitness } & $(5-10)$ weak & 24 & 10.7 \\
\cline { 2 - 4 } & $(10-15)$ average & 310 & 88.5 \\
\cline { 2 - 4 } & $(15-25)$ good & 2570 & 1.2 \\
\hline \multirow{3}{*}{ Honesty } & $(5-10)$ weak & 34 & 42.9 \\
\cline { 2 - 4 } & $(10-15)$ average & 1244 & 55.9 \\
\cline { 2 - 4 } & $(15-25)$ good & 1620 & 13.1 \\
\hline \multirow{3}{*}{ Trust } & $(5-10)$ weak & 380 & 47.8 \\
\cline { 2 - 4 } & $(10-15)$ average & 1386 & 39.1 \\
\hline \multirow{3}{*}{ Total } & $(15-25)$ good & 1132 & - \\
\hline & $(25-50)$ weak & - & 15.2 \\
\hline & $(50-75)$ average & 438 & 84.8 \\
\hline
\end{tabular}

Table III. Results related to the investigation of psychological problems in the research sample

\begin{tabular}{|c|c|c|c|}
\hline Social trust component & Range & Frequency & Percent \\
\hline \multirow{3}{*}{ anxiety } & $0-2.5$ & 2777 & 95.5 \\
\cline { 2 - 4 } & $2.5-4$ & 132 & 4.5 \\
\hline \multirow{3}{*}{ depression } & $0-2.5$ & 2698 & 92.7 \\
\cline { 2 - 4 } & $2.5-4$ & 211 & 7.3 \\
\hline \multirow{3}{*}{ agression } & $0-2.5$ & 2755 & 95 \\
\cline { 2 - 4 } & $2.5-4$ & 145 & 5 \\
\hline \multirow{3}{*}{ sensitivity in relationships } & $0-2.5$ & 2771 & 95.3 \\
\hline \multirow{3}{*}{ ocd } & $2.5-4$ & 138 & 4.7 \\
\cline { 2 - 4 } & $0-2.5$ & 2738 & 94.1 \\
\cline { 2 - 4 } & $2.5-4$ & 171 & 5.9 \\
\cline { 2 - 4 } & $0-2.5$ & 2777 & 95.5 \\
\hline
\end{tabular}

highest scores, and aggression has the lowest scores. And there is no statistically significant difference between men and women in the dimensions of psychological problems $(\mathrm{p}>0.05)$ (Table IV).

According to the study results, there is no significant relationship between any of the demographic variables with the variables of social trust and the dimensions of psychological problems $(\mathrm{p}>0.05)$ (Table V).

Furthermore, the dimensions of social trust can predict $2 \%$ of changes related to anxiety in total with a correlation of $16 \%$, can predict $3 \%$ of changes related to depression with a correlation of $19 \%$, can predict $3 \%$ of changes related to the aggression with a correlation of $15 \%$, can predict $3 \%$ of changes in interpersonal sensitivity with an $18 \%$ correlation, and can predict $4 \%$ of changes related to obsessive-compulsive disorder scores with a $22 \%$ correlation. 
Table IV. Dimensions of psychological problems

\begin{tabular}{|c|c|c|c|c|c|}
\hline & Gender & Mean & Std. Deviation & $\begin{array}{c}\text { Mean } \\
\text { Difference }\end{array}$ & sig \\
\hline \multirow{3}{*}{ anxiety } & male & 19.85 & 7.47 & \multirow{3}{*}{-.39489} & \multirow{3}{*}{.199} \\
\hline & female & 20.24 & 7.97 & & \\
\hline & Total & 20.10 & 7.80 & & \\
\hline \multirow{3}{*}{ depression } & male & 28.76 & 10.24 & \multirow{3}{*}{-.52792} & \multirow{3}{*}{.201} \\
\hline & female & 29.29 & 10.63 & & \\
\hline & Total & 29.10 & 10.49 & & \\
\hline \multirow{3}{*}{ agression } & male & 12.23 & 4.63 & \multirow{3}{*}{-.22474} & \multirow{3}{*}{.223} \\
\hline & female & 12.46 & 4.71 & & \\
\hline & Total & 12.38 & 4.68 & & \\
\hline \multirow{3}{*}{ sensitivity in relationships } & male & 19.46 & 6.43 & \multirow{3}{*}{-.22643} & \multirow{3}{*}{.377} \\
\hline & female & 19.68 & 6.56 & & \\
\hline & Total & 19.60 & 6.51 & & \\
\hline \multirow{3}{*}{ ocd } & male & 23.46 & 6.97 & \multirow{3}{*}{-.27524} & \multirow{3}{*}{.328} \\
\hline & female & 23.73 & 7.23 & & \\
\hline & Total & 23.64 & 7.14 & & \\
\hline
\end{tabular}

Table V. Results of examining the correlation between demographic variables and social trust variables, and dimensions of psychological problems

\begin{tabular}{|c|c|c|c|c|c|c|}
\hline & social trust & anxiety & depression & agression & $\begin{array}{l}\text { Sensitivity in } \\
\text { relationships }\end{array}$ & ocd \\
\hline Gender & .010 & .024 & .024 & .023 & .017 & .018 \\
\hline Age & -.010 & .025 & .024 & .031 & .013 & .019 \\
\hline Situation & .002 & .029 & .035 & .036 & .000 & .028 \\
\hline Income & .015 & .015 & .009 & .006 & .001 & .015 \\
\hline Education & -.002 & .005 & .011 & -.016 & .011 & .018 \\
\hline Accommodation & -.005 & -.008 & -.025 & -.029 & -.026 & -.030 \\
\hline
\end{tabular}

\section{DISCUSSION}

The results achieved by the study, there was no statistically significant difference between males and females and single and married people concerning Anxiety caused Corona and psychological problems and social trust and also in terms of the education level. But there is a negative and significant relationship between social trust dimensions and the dimensions of psychological problems.

COVID-19 has many social and economic consequences (10). Quarantine is the most common and best strategy to prevent the spread of the disease during the spread of the disease COVID-19 (8). Implementing quarantine health policies, despite the positive consequences, has caused negative psychological effects in the community. Fear of the disease, death, spreading false news and rumors, interference in daily activities, regulations to prohibit or restrict travel and commuting, reduce social relationships, job and financial problems and dozens of other consequences, and doubt the people's mental health in the community. The most common causes to create stress and psychological disorders in quarantined people due to COVID-19 have included fear of being infected or infect others, long period of quarantine, insufficient support and lack of access to adequate medical care and food, and finally, fatigue and boredom caused by quarantine and isolation. Adding some unpleasant thoughts such as loneliness, stigmatization, denial, hopelessness, and aggression and suicidal thoughts in more severe degrees may ultimately cause people to lose the psychological support from family and friends, which intensifies psychological stress and damages(18).Quarantine causes emotional distress, depression, stress, mood fluctuations, irritability, 
insomnia, decreased attention, post-traumatic stress, and disorder, anger, emotional insensibility $(6,8)$.

This study revealed about $5 \%$ of the various psychological problems, and the most influences caused by the quarantine on the subject's mental health were related to increased depression, anxiety, aggression, etc.

The results of other studies showed that about $1 \%$ of individuals and hospital personnel exhibited severe symptoms of depression 9 years after quarantine.The psychological influence of quarantine is deep-felt and can be permanent. People become anxious and stressed because they do not know the exact timing of the end of the crisis and obligatory isolation (6). This anxiety can cause irritability and increase the risk of violence. In these situations, anxiety can advance to depression, which is a frequent risk because the person feels a lack of social contact severely. This concern is especially higher for people who have already had a mental illness because it is even highly difficult and restricted to access to the doctor and psychiatrist in imprisonment and quarantine conditions. The World Health Organization says quarantine may increase the world's death rate because it raises the risk of cardiovascular disease, diabetes, and obesity and increases the risk of colon cancer, hypertension, osteoporosis, fat metabolism disorders, depression, and anxiety (19).

According to the study results, the majority of the studied subjects behaved based on trust, cooperative tendencies, sincerity, honesty, and confidence, and there was no statistically significant difference between females and males in the social trust variable.

Corona can affect the social indexes in addition to the negative psychological effects such as stress. Critical situations of the disease can cause positive and negative psychological and social effects that can affect people's mental health in society. Hence, it is necessary to examine and explain mental health changes according to psychological and social factors. In conditions of crisis, the social and individual structures of life are disturbed. Disturbance of individual structures means to reduce individual control and the predictability of the life flow. The influence of these conditions on society shows different and dual consequences and effects. On the other hand, it causes a social disturbance, weakens social rules, and increases self-interest with social differences and selfishness. But on the other hand, it may strengthen social solidarity, the people's cooperation, development of charitable activities and non-governmental organizations, strengthening emotional relations and connections, strengthening family and also increasing motivation to work and effort, participation and altruism and in general, it increases participation and social solidarity.

The results of this study also showed that the subject's social trust in quarantine conditions is in a desirable condition. The results of this study also revealed that there is a significant negative relationship between social trust and the dimensions of psychological distress. Studies have revealed that a person's mental health will be threatened in this situation because social support positively affects mental obstinacy and quality of life (6, $8,18)$. The results achieved by this study also confirm this case. So that the dimensions of social trust were able to predict psychological distress.

Adaptive structures may also be created in critical situations. For example, critical situations cause all society members to try and operate to stop and control the disease in a joint move with common purposes and values. In other words, critical situations cause a new meaning in people's social life. In Iranian society, we have perpetually observed in critical situations that new structures based on these values have been developed and have caused social harmony and collective solidarity due to ethnic culture and national and religious values based on unity and solidarity. Critical conditions caused by Corona disease and increasing negative factors such as anxiety have also caused positive factors such as solidarity and social participation, which have a negative and positive effect on mental health (11).Trust increases compliance $(20,21)$ and decreases mortality $(22)$.

\section{CONCLUSION}

As the study results show, although quarantine can cause psychological distress, these effects are moderate. On the other hand, the critical condition of corona disease has increased negative factors such as anxiety and has created positive factors such as social trust, affecting mental health. Consequently, it is recommended to use this important social capacity to maintain and promote society's mental health.

\section{Conflicts of interest}

The authors declared no competing interests.

\section{Ethical considerations}

This study has been approved with the ethical code of IR.SKUMS.REC.1399.016 in Shahrekord University of Medical Sciences.

\section{Funding/Support}

None. 


\section{REFERENCES}

1. Kim AE, Brandstetter E, Graham C, et al. Seattle Flu Study-Swab and Send: Study Protocol for At-Home Surveillance Methods to Estimate the Burden of Respiratory Pathogens on a City-Wide Scale. medRxiv. 2020.

2. Li L. Challenges and priorities in responding to COVID-19 in inpatient psychiatry. Psychiatric Services. 2020:appi. ps. 202000166.

3. Brooks SK, Webster RK, Smith LE, et al. The psychological impact of quarantine and how to reduce it: rapid review of the evidence. The Lancet. 2020.

4. Sun C, Zhai Z. The efficacy of social distance and ventilation effectiveness in preventing COVID-19 transmission. Sustainable cities and society. 2020;62:102390.

5. Henry BF. Social Distancing and Incarceration: Policy and Management Strategies to Reduce COVID-19 Transmission and Promote Health Equity Through Decarceration. Health Education \& Behavior. 2020:1090198120927318.

6. Wang $\mathrm{Y}, \mathrm{Xu} \mathrm{B}, \mathrm{Zhao} \mathrm{G}$, et al. Is quarantine related to immediate negative psychological consequences during the 2009 H1N1 epidemic? General hospital psychiatry. 2011;33(1):75-7.

7. Jiang $\mathrm{X}$, Niu $\mathrm{Y}, \mathrm{Li} X$, et al. Is a 14-day quarantine period optimal for effectively controlling coronavirus disease 2019 (COVID-19)? medRxiv. 2020.

8. Rubin GJ, Wessely S. The psychological effects of quarantining a city. Bmj. 2020;368.

9. Song K, Li T, Luo D, et al. Psychological Stress and Gender Differences during COVID-19 Pandemic in Chinese Population. medRxiv. 2020.

10. Van de Walle S, Bouckaert G. Public service performance and trust in government: The problem of causality. International Journal of Public Administration. 2003;26(8-9):891-913.

11. Van Bavel JJ, Baicker K, Boggio PS, et al. Using social and behavioural science to support COVID-19 pandemic response. Nature Human Behaviour. 2020:1-12.

12. Kye B, Hwang S-J. Social trust in the midst of pandemic crisis: Implications from COVID-19 of South Korea. Research in social stratification and mobility. 2020;68:100523.

13. Blair RA, Morse BS, Tsai LL. Public health and public trust: Survey evidence from the Ebola Virus
Disease epidemic in Liberia. Social Science \& Medicine. 2017;172:89-97.

14. Morse B, Grépin KA, Blair RA, Tsai L. Patterns of demand for non-Ebola health services during and after the Ebola outbreak: panel survey evidence from Monrovia, Liberia. BMJ Global Health. 2016;1(1).

15. Siegrist M, Zingg A. The role of public trust during pandemics: Implications for crisis communication. European psychologist. 2014;19(1):23.

16. Anisi J, Akbari F, Madjian M et al. Standardization of mental disorders symptoms checklist 90 revised (SCL-90-R) in army staffs. 2011.

17. Saffarinia M, Kheiraldin Z. Construction and standardization of administrative corruption perception questionnaire and its relationship with social trust. IJABR. 2016;7:437-45.

18. $\mathrm{Wu} \mathrm{Z}$, McGoogan JM. Characteristics of and important lessons from the coronavirus disease 2019 (COVID-19) outbreak in China: summary of a report of 72314 cases from the Chinese Center for Disease Control and Prevention. Jama. 2020;323(13):1239-42.

19. Saffarinia M. The prediction of mental health based on the anxiety and the social cohesion that caused by Coronavirus. Social Psychology Research. 2020;9(36):129-41.

20. Han Q, Zheng B, Cristea M, et al. Trust in government and its associations with health behaviour and prosocial behaviour during the COVID-19 pandemic. 2020.

21. Olsen AL, Hjorth F. Willingness to Distance in the COVID-19 Pandemic.

22. Oksanen A, Kaakinen M, Latikka R, et al. Regulation and Trust: 3-Month Follow-up Study on COVID-19 Mortality in 25 European Countries. JMIR Public Health and Surveillance. 2020;6(2):e19218.

Received: 14.04.2021

Accepted for publication: 15.05 .2021

\section{Address for correspondence:}

Ayda Hasanpour Dehkordi

Department of Psychology, Shahrekord Azad University, Shahrekord, Iran

e-mail: Ayda_hnp97@yahoo.com

https://orcid.org/0000-0001-8085-4011 